\title{
Prevalence of work related musculoskeletal disorders among women tea factory workers of Nilgiri: An ergonomic study
}

\section{Gayathri Devi*}

Department of Resource Management and Consumer Sciences, College of Home Science, Professor Jayashankar Telangana State Agriculture University, Hyderabad500030 (Telangana), India

\section{Aditi Vats}

Family Resource Management, Govind Ballabah Pant University of Agriculture and Technology, Pantnagar (Uttarakhand), India

${ }^{*}$ Corresponding author. E-mail:gdevi6789@gmail.com

\begin{abstract}
This research study is about the prevalence of work related musculoskeletal disorders among women tea factory workers of Nilgiri. The purposive random sampling method was used to select the respondents. The work related to musculoskeletal disorders or discomfort and the pain experienced by the workers were determined by using Standardized Nordic Questionnaire Work related activities taken as independent variable; pain and discomforts taken as dependent variable. Work related pain/ discomfort was reported in 12-month, last month and prevalence in 7 days during May 2015 to April 2016. Workers reported that musculoskeletal pain for the 12 months according to body parts especially on the neck $(80 \%)$, shoulders $(60 \%)$, lower back $(87.5 \%)$, hips $(80 \%)$, knees $(72.5 \%)$ and wrists $(25 \%)$ due to their daily activities in the factories which were lifting, lifting above the shoulder level, lifting with one shoulder, pushing, pulling loads more than $25 \mathrm{kgs}$. By implementing ergonomic interventions like improved work organization with job rotations and ample rest during work of the tea factory workers will reduce their musculoskeletal disorders symptoms and pain.
\end{abstract}

Keywords: Discomfort, Musculoskeletal disorders, Tea factory, Women workers, Work

\section{Article Info}

DOI:10.31018/jans.v10i3.1786 Received: June 5, 2018

Revised: August 6, 2018

Accepted: August 14, 2018

\section{How to Cite}

Devi, M.G. and Vats, A (2018). Prevalence of work related musculoskeletal disorders among women tea factory workers of Nilgiri: An ergonomic study. Journal of Applied and Natural Science, 10 (3): 990 - 994

\section{INTRODUCTION}

India is the second largest producer of tea in the world, producing an average of 1100 M.Kgs per year (Tea board India) and women is the major labour force of the industry. The joining of women in the workforce is increasing day by day, especially in industry and service sector where repetitive work is required. Due to their low literacy level and lack of technical knowledge, mostly women workers are engaged in occupations with repetitive, monotonous and low-paid work. The sectors like agriculture, agro based industry (tea, fruit processing, cottage industries, etc) and services women workers are the prime workforce. Generally they handle two or more tasks simultaneously. They are therefore prone to suffer from workrelated diseases, which are further complicated by social, psychological and physiological issues. The exposure of women workers to these issues may affect them in one or more of three ways: health, performance, and comfort. (Bhattacharyya et al., 2012).

Musculoskeletal disorders (MSDs) are injuries and disorders from muscles, nerves, tendons, liga- ments, joints, cartilage and spinal discs (Choi et al., 2007). Individual factors like age, sex, anthropometric, dimensions, muscle strength and physical fitness, lack of task variation, insufficient rest break, psychological and social factors contribute to musculoskeletal disorders (Gardner et al. 2002). Performing forceful exertions requires an application of considerable contraction forces by the muscles, which causes them to fatigue rapidly (Hagen et al 2002). Therefore, excessive to forceful exertions also lead to overuse of muscles and may result in muscle strain, soreness and damage. Performing forceful exertions can also irritate tendons, joints and discs, which lead to inflammation, fluid build-up, and constriction of blood vessels and nerves in the area (Kerr et al., 1998).

Tea factory workers have to adopt awkward posture that causes low back pain and injury in the work place poor sitting, lifting and carrying during the work. The causative factors among tea factory workers are poor working posture, manual handling, repetitive movement, twisting and bending and forceful movement etc. So, the present study was aim to examine the prevalence of work relat- 
Devi, M.G. and Vats, A. / J. Appl. \& Nat. Sci. 10 (3): 990 - 994 (2018)

ed musculoskeletal disorders among women tea factory workers.

\section{MATERIALS AND METHODS}

Selection of subject and field: For the present study, purposive sampling method was used to select the 40 women respondents from the age group of $30-60$. The main reason for selection of women workers was that women played the major role in the processing works. Frequency and percentage were used to analyse the data.

Standardized Nordic questionnaire allows comparison of low back, neck, shoulder and general complaints for use in epidemiological studies.It can be used as a questionnaire or structured interview. So, for this study Revised Nordic questionnaire was used to assess the musculoskeletal disorders of the respondents. Respondents were asked if they had any musculoskeletal trouble in the last 12 months, last one month and one week or last seven days which prevented from normal daily activities i.e. cooking, washing clothes and other household activities.

\section{RESULTS AND DISCUSSION}

Activities that caused pain and discomfort: It was found that 85 per cent of respondents made complaint of pain during lifting of bag and approximately 63 per cent respondents reported that they were having pain during the activity and filling tea powder in bags. While doing the activity of handling sacks, nearly 73 respondents were exposed to pain or discomfort. Approximately 78 per cent of respondents were subjected to discomfort or pain during stacking of sacks and tipping of tea powder into hopper. Half of the respondents suffered during the activities such as loading wheel barrow, wheeling and blending cause pain. About

Table 1. Prevalence of musculoskeletal pain/ discomfort among tea factory workers on the basis of 12 months recall period $(n=40)$.

\begin{tabular}{lll}
\hline Body parts & Frequency & Percentage (\%) \\
\hline Neck & 32 & 80 \\
Shoulder & & \\
Right & 3 & 7.5 \\
Left & 4 & 10 \\
Both & 24 & 60 \\
Elbow & & \\
Right & 5 & 12.5 \\
Left & 15 & 37.5 \\
Both & 5 & 12.5 \\
Wrist/hands & & \\
Right & 7 & 17.5 \\
Left & 2 & 5 \\
Both & 10 & 25 \\
Upper back & 18 & 45 \\
Lower back & 35 & 87.5 \\
Hips/ thighs & 32 & 80 \\
Knees & 29 & 72.5 \\
Ankles/feet & 31 & 77.5 \\
\hline \hline
\end{tabular}

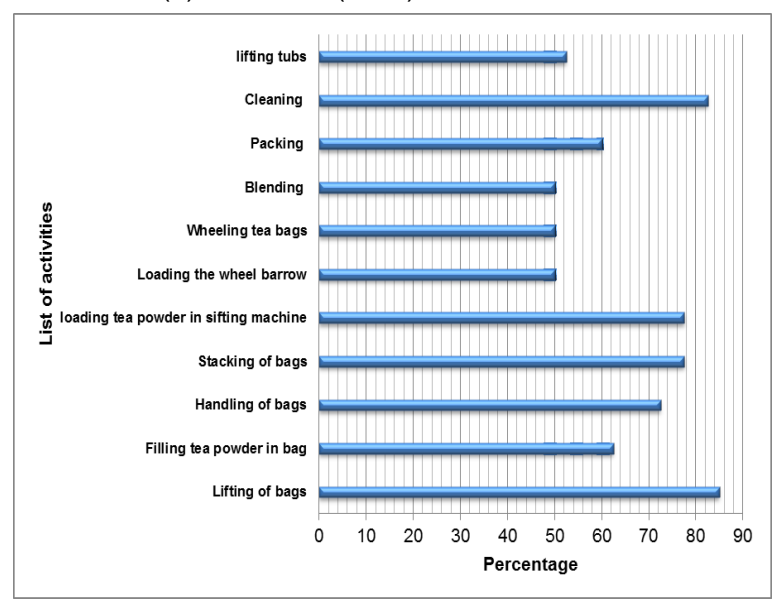

Fig.1.Distribution of respondents on the basis activities that caused pain and discomfort.

60 per cent of respondents reported that they faced discomfort while performing the activity of packing. It was recorded that almost 83 per cent of respondents were suffering pain while cleaning (Fig.1).

Self-reported pain discomfort: It was reported that for the last 12 months, 80 per cent of the respondents suffered pain and discomfort in neck. Sixty per cent of respondents had pain in both shoulders. Whereas 10 per cent of respondents had pain in left shoulder and 7.5 per cent respondents had pain in left shoulder. Regarding pain in elbow approximately 13 per cent respondents had pain in right and both wrist but in the case of left wrist it seemed that nearly 38 per cents of respondents had pain. Approximately 18 per cent respondents had pain in the right wrist or hand and same per cent of respondents experienced pain in both hand. Only five per cent of respondents had pain in left hand or wrist. Forty five re-

Table 2. Prevalence of musculoskeletal pain/ discomfort among tea factory workers on the basis of one month recall period $(n=40)$.

\begin{tabular}{lll}
\hline Body parts & Frequency & Percentage (\%) \\
\hline Neck & 27 & 67.5 \\
Shoulder & & \\
Right & 3 & 7.5 \\
Left & 3 & 7.5 \\
Both & 24 & 60 \\
Elbow & & \\
Right & 5 & 12.5 \\
Left & 16 & 40 \\
Both & 7 & 17.5 \\
Wrist/hands & & \\
Right & 7 & 17.5 \\
Left & 2 & 5 \\
Both & 8 & 20 \\
Upper back & 16 & 40 \\
Lower back & 32 & 80 \\
Hips/thighs & 32 & 80 \\
Knees & 24 & 60 \\
Ankles/feet & 30 & 75 \\
\hline
\end{tabular}


Devi, M.G. and Vats, A. / J. Appl. \& Nat. Sci. 10 (3): 990 - 994 (2018)

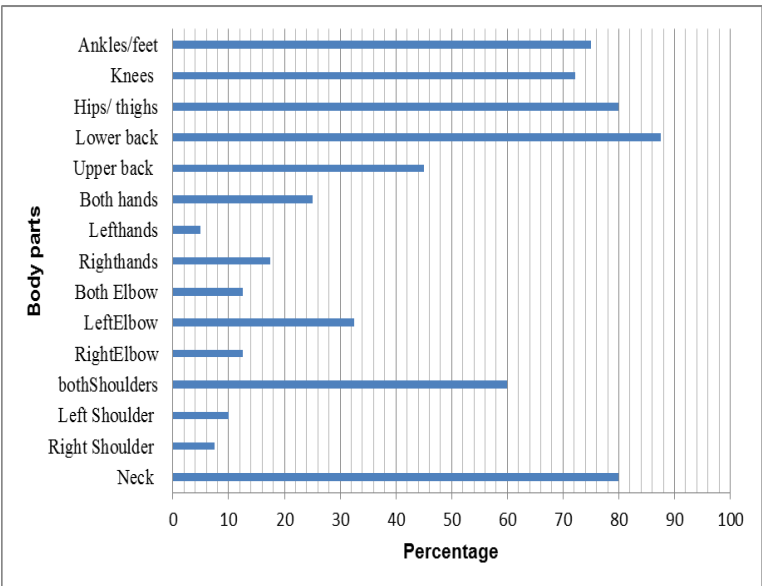

Fig.2. Distribution of respondents on the basis of prevalence of musculoskeletal pain/discomfort 12 month recall period.

spondents had pain in upper back. Almost 88 per cent of respondents experienced pain in lower back. Besides, 80 per cent of respondents had pain in thighs/hips. Around 73 per cent of respondents experienced pain in knees. Nearly 76 per cent of respondents experienced pain in the ankles.

During last the 12 months, 80 per cent of the respondents suffered pain and discomfort in neck. Sixty per cent of respondents had pain in both shoulders. Whereas 10 per cent of respondents had pain in left shoulder and 7.5 per cent respondents had pain in left shoulder. Regarding pain in elbow approximately 13 per cent respondents had pain in right and both wrist but in the case of left wrist it seemed that nearly 38 per cents of respondents had pain. It was reported that approximately 18 per cent respondents had pain in the right wrist or hand and same per cent of respondents experienced pain in both hand.

Table 3. Prevalence of musculoskeletal pain/ discomfort among tea factory workers on the basis of 7 days recall period $(n=40)$.

\begin{tabular}{lll}
\hline Body parts & Frequency & Percentage (\%) \\
\hline Neck & 25 & 62.5 \\
Shoulder & & \\
Right & 2 & 5 \\
Left & 4 & 10 \\
Both & 24 & 60 \\
Elbow & & \\
Right & 5 & 12.5 \\
Left & 16 & 40 \\
Both & 3 & 7.5 \\
Wrist/hands & & \\
Right & 6 & 15 \\
Left & 2 & 5 \\
Both & 10 & 25 \\
Upper back & 17 & 42.5 \\
Lower back & 32 & 80 \\
Hips/ thighs & 33 & 82.5 \\
Knees & 29 & 72.5 \\
Ankles/feet & 30 & 75 \\
\hline \hline
\end{tabular}

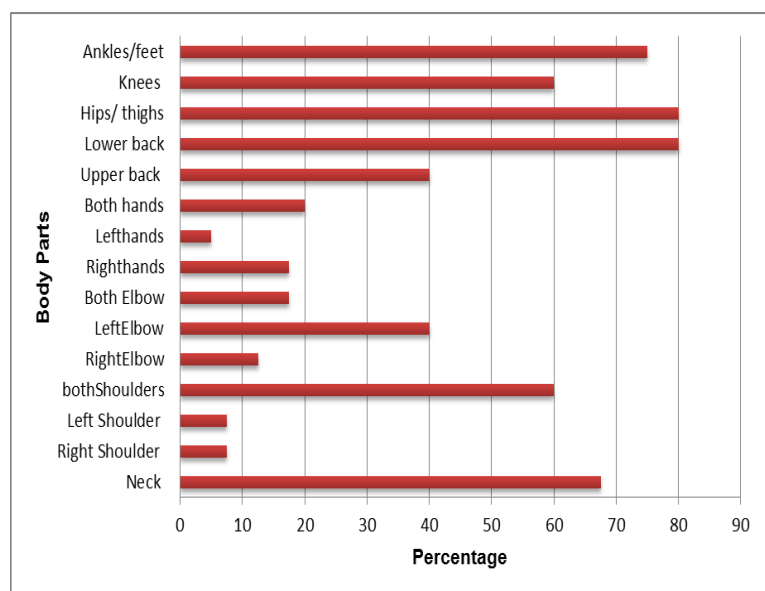

Fig. 3. Distribution of respondents on the basis of prevalence of musculoskeletal pain/discomfort one month recall period.

Only five per cent of respondents had pain in left hand or wrist. Forty five respondents had pain in upper back. Almost 88 per cent of respondents experienced pain in lower back. It was reported that 80 per cent of respondents had pain thighs/ hips. Around 73 per cent of respondents experienced pain in knees and in ankles nearly 76 per cent of respondents were having pain (Fig.2,Table 1).

In the case of pain during last one month, nearly 68 per cent of respondents experienced pain neck .Sixty per cent of respondents reported pain in both shoulders and also 8 per cent of respondent complained that pain in left shoulder as well as in right shoulder. Concerning pain in elbows 40 per cent of respondents reported pain in left elbow, nearly 13 per cent of respondents reported pain in right elbow and 40 per cent of respondents had pain in left elbow. Almost 18 per cent of respondents had pain in both elbows. The data show that approximately 18 per cent of respond-

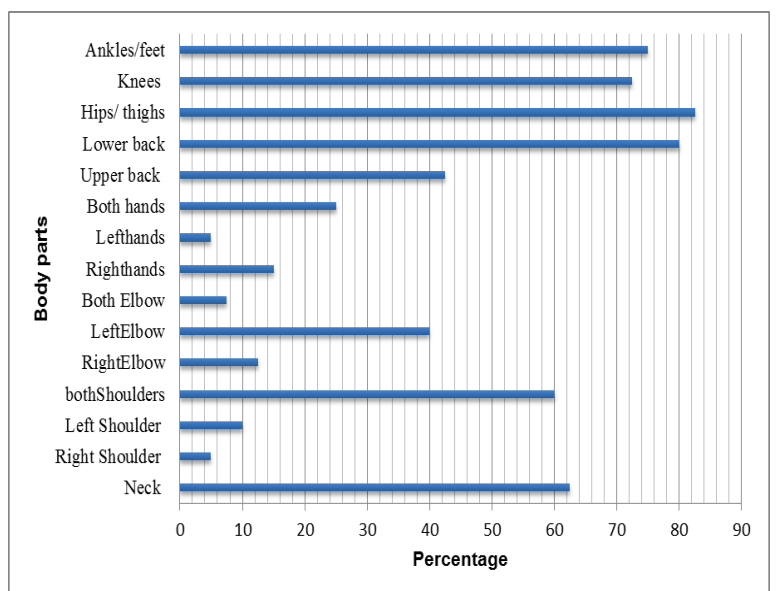

Fig.4. Distribution of respondents on the basis of prevalence of musculoskeletal pain/discomfort during7 days recall period. 
ents experienced pain right hand / wrist and only 5 per cent of respondents reported pain in left wrist/ hand. Twenty per cent of respondents had pain in both wrist hands. It was found that 40 per cent of respondents had discomfort in upper back. Most of the respondents had pain in both low back and thighs. On the other hand 60 per cent of respondents experienced pain in knees. One third of respondents from whole sample complained pain in ankles (Fig.3,table 2).

Further, it was revealed that almost 63 per cent of workers reported pain in neck and for shoulder the responses were 5, 10 and 60 per cent for right, left and both shoulders. Forty per cent of respondents complained pain in left elbows but the incidence of pain in right and both elbows were nearly 13 and 8 per cent. Almost one third of respondents experienced pain in both wrist and the percentage of pain in right and left hands were 15 and 5 respectively. Most of the respondents $(80 \%)$ complained pain in lower back but for upper back the incidence was less than lower back. Almost 83 per cent of respondents had pain in thighs and the percentage for knees and ankles were 73 per cent and 75 per cent respectively(Fig.4, table 3).

Neck, lower back, ankle/feets, thigh and shoulders highly prone to MSD due to following manual activities such as lifting of bags, loading of tea powder in sifting machine, staking, cleaning where respondents had carried load above shoulder level and to carry the load from one place to another place in the work area. Shahu et al. (2010) reported that female construction workers highly exposed to low back pain followed by knees, neck, shoulder, elbows and wrists. In addition, Hossain et al. (2018) stated that prevalence of work related musculoskeletal disorders among women readymade garment worker was high in lower back followed by neck and knees.

The data showed that more than half of the respondents perceived the problem during working in factory. Almost 45 per cent of respondents noticed the problem before working in factory. Responses regarding to medical treatment irrespective of respondents has undergone for the treatment of problems and they take treatment from the personal doctors not from factory medical, self and others. Whereas, while during working hours respondents come across severe injuries like fractures and mechanical injuries and they were facilitated to claim the medical expenses from the concern management authority.

With respect to the problems for which they take the treatment exhibit that on an average 90 per cent of respondents had taken treatment for cough $(87.5 \%)$, cold $(90 \%)$ and back pain (85 \%) majority ( 80 per cent) of the respondents had undergone treatment for head ache and shoulder pain. Almost 78 per cent of respondents had taken treatment for body pain; whereas 35 per cent of respondent agreed that they had taken treatment for irritation in eyes. It was found that 60 per cent of respondents had taken treatment for pain in cuff muscles. Half of the respondents reported that they had undergone treatment for irritation in eyes, stiffness in hand joints, burning sensation in hands, pain palm, forearm pain, pain in trunk, and numbness in fingers. Only 5 per cent of respondents had taken medical treatment for fractures. Only 10 per cent of results were found positive.

Respondents were allowed take rest during lunch and tea breaks twice in a day i.e. lunch break-1530 minutes and tea break 10 minutes. Insufficient rest between different activities aggravate the pain in the body parts. Women has play dual role such as home maker and employee so, there is no chance to take rest at home. Prolonged exposure to pain in body parts limits respondents from doing household activities.

\section{Conclusion}

The ergonomic risk factors faced by tea factory workers while performing their daily activities in the factories are lifting, lifting above the shoulder level, lifting with one shoulder, pushing, pulling loads more than $25 \mathrm{kgs}$. This was in line with the high prevalence of workers having musculoskeletal pain for the 12 months according to body parts especially on the neck $(80 \%)$, shoulders $(60 \%)$, lower back $(87.5 \%)$, hips $(80 \%)$, knees $(72.5 \%)$ and wrists $(25 \%)$. Implementing ergonomic interventions like improved work organization with job rotations and ample rest during work to the tea factory workers may reduce the musculoskeletal disorders symptoms and pain among tea factory workers.

\section{REFERENCES}

1. Bhattacharyya, N and Chakrabarti, D. (2012). Ergonomic basket design to reduce cumulative trauma disorders in tea leaf plucking operation, work, IOS Press, 41,1234-1238

2. Choi, B.K.L., Verbeek, J.H., Jiang, Y. and Tang, J.L. (2007). Exercises for prevention of recurrences of low -back pain. Cochrane Database of Systematic Reviews: Protocols.

3. Gardner, L.I., Landsittel, D.P., Nelson, N.A. and Pan, C.S. (2002). Misclassification of physical work exposures as a design issue for musculoskeletal intervention studies. Scandinavian Journal of Work, Environment and Health, 26 (5):406-413

4. Hagen, K.B., Hilde, G., Jamtvedt, G. and Winnem, M.F. (2002). The Cochrane review of advice to stay active as a single treatment for low back pain and sciatica. Spine, 27(16):1736-1741

5. Hossain M.D, Aftab A, Al Imam M.H, Mahmud I, Chowdhury I.A, Kabir R.I. (2018). Prevalence of work related musculoskeletal disorders (WMSDs) and ergonomic risk assessment among readymade garment workers of Bangladesh: A cross sectional study. PLOS ONE. 13(7)

6. Kerr, M.S. (1998). A case-control study of biomechanical and psychosocial risk factors for low back- 
Devi, M.G. and Vats, A. / J. Appl. \& Nat. Sci. 10 (3): 990 - 994 (2018)

pain reported in an occupational setting. University of Toronto, PhD. Thesis.

7. Shahu, S., Chattopadhyay,S., Basu,K. andPaul,G. (2010). The ergonomic evaluation of work-related musculoskeletal disorders among construction labourers working in unorganized sectors in West Bengal, India. J. Human Ergol., 39: 99-109 